\section{Evidence for Qualitative Suppression of Red Skin Color in Peach}

\author{
T.G. Beckman ${ }^{1}$ \\ United States Department of Agriculture, Agricultural Research Service, \\ Southeastern Fruit and Tree Nut Research Laboratory, Byron, GA 31008
}

\author{
J. Rodriguez Alcazar ${ }^{2}$ \\ Programe de Fruticultura, Colegio de Postgraduados, Montecillo, Mexico 56230 \\ W.B. Sherman ${ }^{2}$ \\ Horticultural Science Department, University of Florida, Gainesville, FL 32611
}

\begin{abstract}
D.J. Werner ${ }^{2}$
Department of Horticultural Science, North Carolina State University, Raleigh, NC 27695
\end{abstract}

Additional index words. Prunus persica, breeding

\begin{abstract}
Recently observed hybrid populations of peach [Prunus persica (L.) Batsch] provide evidence for the presence of a single gene suppressing red skin color. The fruit of seedling populations of FL90-48C and FL90-37C $\times$ FL84-18C, FL90-50CN $\times$ FL92-2C, FL90-48C $\times$ FL91-12, FL91-8 $\times$ FL88-6, and open-pollinated or selfed populations from unselected seedlings of 'Contender' $\times$ PI65977 ('Giallo di Padova') and 'Mexico Selection' $\times$ 'Oro A' were rated for normal quantitative vs. no anthocyanin skin color at maturity. At this stage of development, anthocyaninless phenotypes displayed no red color over the entire surface of the fruit. Instead they were characterized by a bright yellow ground color that stood out visually in the seedling rows, and which was dubbed highlighter. The two crosses with FL84-18C yielded populations that approximated a 1:1 segregation ratio for quantitative red:no red skin color. All other crosses produced populations that closely approximated a 3:1 segregation ratio for quantitative red to no red. These data are consistent with the hypothesis that the highlighter phenotype is a single gene recessive trait. We propose the gene symbols of $h$ and $H$ for the recessive no red (highlighter) and dominant normal quantitative red (wild-type) alleles, respectively.
\end{abstract}

Red skin color is a desirable trait contributing to the attractiveness of a peach [Prunus persica (L.) Batsch]. Hence, high levels of red blush are sought in most breeding programs developing cultivars for the fresh market (Scorza and Sherman, 1996). In contrast, most breeding programs developing cultivars for the canning industry generally place a premium on reduced red coloration in any part of the fruit because of the possibility of staining in the processed product (Gradziel et al., 1993). Several reports have been published on the expression and inheritance of red skin color (Blake, 1932, 1940; Hansche, 1986; Weinberger, 1944) all of which concluded that it was under the control of multiple genes. However, a recent report (Beckman and Sherman, 2003) showed evidence for qualitative control of $100 \%$ red skin color. We present evidence for the presence of qualitative gene action suppressing anthocyanin production in the epidermis of peach fruit.

The breeding programs at Montecillo, Mexico and at the University of Florida, are developing cultivars for the fresh market and have used nonmelting flesh materials from a variety of sources including selections developed

\footnotetext{
Received for publication 3 Nov. 2004. Accepted for publication 11 Dec. 2004

${ }^{1}$ Research horticulturist.

${ }^{2}$ Professor.
}

for processing industries and Criollo markets in Central America, both of which typically desire fruit with little or no red blush. These programs have used FL84-18C and 'Oro A' as parents both of which display no red skin color (Okie, 1998). Additionally, the fresh market breeding program at North Carolina State University has made several crosses with PI65977 ('Giallo di Padova'), a melting-flesh selection from Italy that produces no anthocyanin in the fruit (Werner and Okie, 1998). In several populations generated in these programs either with these parents or with selections developed from them, an unusually large proportion of seedlings appeared which developed no red skin coloration as the fruit approached maturity. The observed variation in red skin color did not appear to be controlled by quantitative factors in these populations. These seedlings typically developed a bright yellow ground color that stood out dramatically in the seedling rows, hence, it was dubbed highlighter. Moreover, upon closer inspection it was observed that there was no anthocyanin development in the fruit flesh or at the pit as well.

The highlighter phenotype differs from both the anthocyaninless (An) (Monet, 1967) and the white flower (W) (Lammerts, 1945) loci of peach. The anthocyaninless (an/an) phenotype is characterized as a reduced intensity of red coloration in flower petals, sepals and damaged leaf tissues. Some trace of red skin blush can appear on the fruit surface but the twig epidermis is free of red coloration even when fully exposed to the sun. The white flower (w/w) phenotype is characterized as the complete absence of red coloration in any plant tissue. In the highlighter $(\mathrm{h} / \mathrm{h})$ phenotype, anthocyanin development appears to be suppressed only in the fruit tissues. Leaf injury sites, twig epidermis, bud scales, flower petals, anthers, and stipules all display red coloration, albeit at a somewhat reduced intensity in some cases.

In those crosses involving a highlighter phenotype as one of the parents, i.e., FL84-18C which was used as a pollen parent in crosses with FL90-48C and FL90-37C, segregation ratios approach 1:1, normal quantitative red: no red, while those involving two normal quantitative red phenotype individuals or an open-pollinated population from one such individual, segregation ratios approach 3:1, normal quantitative red:no red (Table 1). In seven of the eight populations studied there appeared to be an excess of normal quantitative red types. In the absence of cages to prevent insect mediated outcrossing, a surplus of normal quantitative red phenotypes would be expected as the highlighter gene is probably rare and most outcrosses would result in normal quantitative red phenotypes. The only population that did not appear to have an excess of quantitative red phenotypes, (Contender $\times$ PI65977) $F_{2}$, was a caged self which would have precluded the possibility of insect-mediated outcrossing.

These data are consistent with the hypothesis that the highlighter phenotype is a single gene recessive trait. We propose that the recessive allele suppressing anthocyanin development in peach epidermis and flesh is present in the homozygous state in FL84-18C, 'Oro A' and PI65977 and that FL88-6, FL90-37C, FL90-48C, FL90-50CN, FL91-8C, FL91-12, and FL92-2C are heterozygous. 'Contender' and 'Mexican Selection' are probably homozygous for the dominant allele. We propose the gene symbols of $h$ and $H$ for the recessive anthocyanin suppression ('highlighter') and dominant partial red (wild-type) alleles, respectively.

This trait should prove useful in breeding processing type peaches as red skin color development is completely suppressed even at full maturity. The highlighter trait in the University of Florida and Mexico programs probably came from 'Criollo' peaches, many of which are low quantitative or no red skin color phenotypes. It is possible that this trait may already be present in processing peach germplasm and merely passing unnoticed in low quantitative red skin color genetic backgrounds.

\section{Literature Cited}

Beckman, T.G. and W.B. Sherman. 2003. Probable qualitative inheritance of full red skin color in peach. HortScience 38:1184-1185.

Blake, M.A. 1932. The J.H. Hale as a parent in peach crosses. Proc. Amer. Soc. Hort. Sci. 29:131-136.

Blake, M.A. 1940. Some results of crosses of early ripening varieties of peaches. Proc. Amer. Soc. Hort. Sci. 37:232-241. 
Table 1. Distribution of partial red skin color phenotypes and anthocyaninless skin color phenotypes.

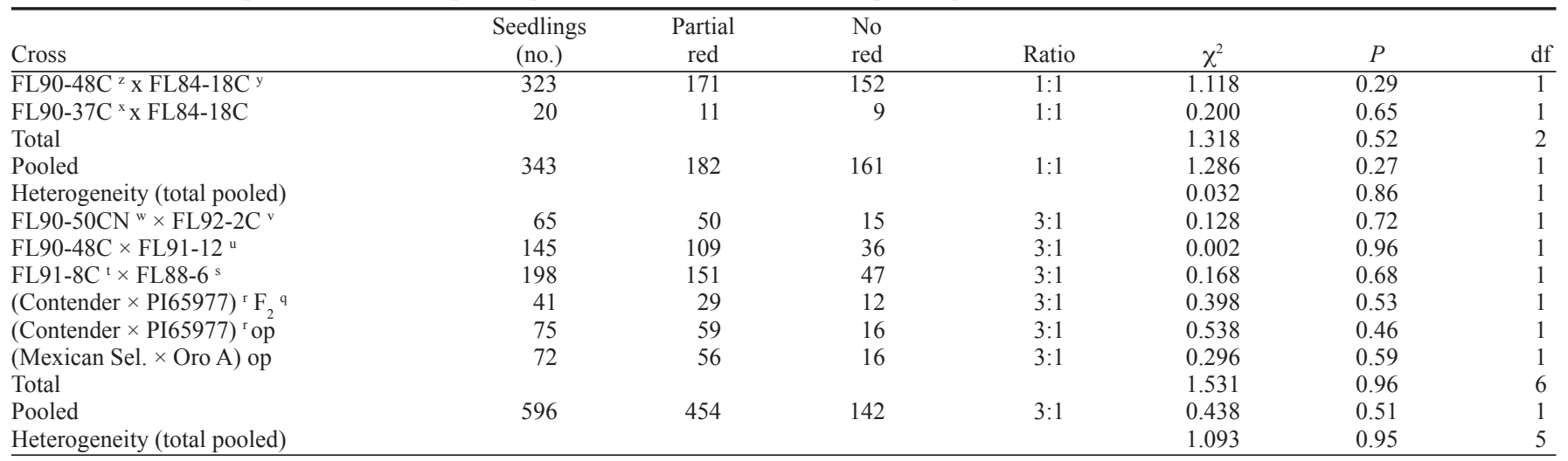

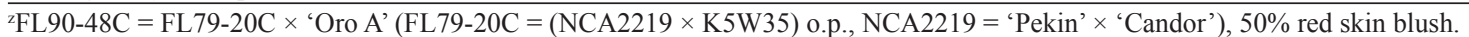

${ }^{y} \mathrm{FL} 84-18 \mathrm{C}=($ 'Oro A' $\times$ 'Sunmist') o.p., $0 \%$ red skin blush.

${ }^{\times}$FL90-37C $=$FL79-26C $\times$'Oro A', (FL79-26C $=$'Sunred' $\times$'Mexican Cling'), 70\% red skin blush.

wFL90-50CN $=$ FL84-18C $\times$ FL79-20C, 100\% red skin blush.

${ }^{\vee} \mathrm{FL} 92-2 \mathrm{C}=\mathrm{FL} 86-28 \mathrm{C} \times$ 'Oro A', (FL86-28C = FL79-20C o.p.), 30\% red skin blush.

"FL91-12 = FL79-20C $\times$ 'Flordaking', 30\% red skin blush.

'FL91-8C $=$ FL79-26C $\times$ 'Oro A', 50\% red skin blush.

'FL88-6 = 'Flordaking' × 'FL79-26C', 20\% red skin blush

'Unselected seedling.

${ }^{\mathrm{T}}$ Tree caged to exclude pollinating insects.

Gradziel, T.M., W. Beres, and K. Pelletreau. 1993. Inbreeding in California canning clingstone peach cultivars. Fruit Var. J. 47:160-168.

Hansche, P.E. 1986. Heritability of fruit quality traits in peach and nectarine breeding stocks dwarfed by the $d w$ gene. HortScience 21:1193-1195.

Lammerts, W.E. 1945. The breeding of ornamental edible peaches for mild climates. I. Inheritance of tree and flower characters. Amer. J. Bot. 32:53-61.

Monet, R. 1967. A contribution to the genetics of peaches. Ann. Amelior. Plantes 17:5-11.

Okie, W.R. 1998. Handbook of peach and nectarine varieties. USDA Agr. Hdbk. No. 714.

Scorza, R. and Sherman, W.B. 1996. Peaches, p. 325-40. In: J. Janick and J.N. Moore (eds.).
Fruit breeding. vol. 1. Tree and tropical fruits. Wiley, New York.

Weinberger, J.H. 1944. Characteristics of the progeny of certain peach varieties. Proc. Amer. Soc. Hort. Sci. 45:233-238.

Werner, D.J. and W.R. Okie. 1998. A history and description of the Prunus persica plant introduction collection. HortScience 33:787-793. 